www.periodicos.unimontes.br/index.php/caminhosdahistoria

\title{
"A ESCOLA DAS MENINAS": REFLEXÕES ACERCA DA FEMINIZAÇÃO DISCENTE NA FAFIL/FUNM NA DÉCADA DE 1960
}

\section{César Rota Júnior ${ }^{1}$}

Resumo: O presente artigo tem por objetivo discutir alguns aspectos do processo de feminização discente, pautando-se na Faculdade de Filosofia, Ciências e Letras - FAFIL, parte da Fundação Norte-mineira de Ensino Superior - FUNM, na década de 1960, enquanto caso ilustrativo. O levantamento documental, em fontes primárias, privilegiou os primeiros cinco anos de funcionamento da referida escola de ensino superior, com foco nos alunos ingressantes, por meio das listas de concurso vestibular do referido período. Há um predomínio feminino na busca pelo curso superior de Pedagogia, em detrimento dos cursos de Letras, História e Geografia, até 1967, e também de Filosofia, Ciências Sociais e Matemática, no ano de 1968. Tal desequilíbrio desencadeou algumas reflexões acerca das motivações de tal realidade social e educacional do norte de Minas, entendendo que a categoria gênero pode contribuir com sua compreensão. Nota-se que há, neste caso, o estabelecimento de uma relação direta entre as características do posto de trabalho e as pretensas características do trabalhador, associando assim pretensas características femininas, como o cuidado com a infância, próxima à uma figura materna.

Palavras-chave: Historiografia da educação; gênero, trabalho docente, ensino superior, norte de Minas.

Abstract: This article aims to discuss some aspects of the student feminization process, based on the Faculty of Philosophy, Sciences and Letters - FAFIL, part of the Fundação Nortemineira de Ensino Superior - FUNM, in the 1960s, as an illustrative case. The documentary investigation, in primary sources, privileged the first five years of operation of the aforementioned higher education school, with a focus on incoming students, through the lists of entrance exams for that period. There is a female predominance in the search for Pedagogy, over others courses like Literature, History and Geography, until 1967, and also in Philosophy, Social Sciences and Mathematics, in 1968. Such imbalance triggered some reflections about the motivations of such a social and educational reality in the north of Minas Gerais, understanding that the gender category can contribute to its understanding. It is noted that, in this case, there is the establishment of a direct relationship between the characteristics of the job and the alleged characteristics of the worker, thus associating alleged female characteristics, such as childcare, close to a maternal figure.

Keywords: historiography of education; gender, teaching work, higher education, northern Minas.

\footnotetext{
${ }^{1}$ Psicólogo, Doutor em Educação (FAE/UFMG). Professor do Centro Universitário FIPMoc (UNIFIPMOC) e do Programa de Pós-Graduação em Educação (PPGE/UNIMONTES). E-mail: cesarota@yahoo.com.br. ORCID: https://orcid.org/0000-0002-6346-3972. O presente artigo descreve pesquisa realizada para a disciplina "Tópicos Especiais em Poder e Processos Socioeconômicos: Trabalho e Gênero", sob a orientação da Prof ${ }^{a}$. Dr ${ }^{\mathrm{a}}$. Sarah Jane Alves Durães.
} 


\section{Introdução}

O presente trabalho pauta-se no uso do gênero enquanto categoria analítica, já que este possibilita uma maior amplitude de compreensão dos fenômenos sociais. O faz quando agrega à ideia de divisão social do trabalho a ideia de divisão sexual do trabalho, partindo da premissa de que as relações de gênero também exercem um papel fundamental na desigual distribuição de mulheres e homens no mercado de trabalho, e uma também desigual remuneração, mesmo quando uma mulher e um homem ocupam o mesmo cargo e possuem o mesmo nível de escolarização.

A utilização da categoria 'gênero' tem sido cada vez mais frequente, já que ele abre espaço à caracterização das relações sociais entre os sexos, e utilizá-lo enquanto categoria analítica exige, necessariamente, a superação da explicação de cunho puramente biológica entre homens e mulheres, além de trazer, implicitamente, que qualquer estudo da situação social das mulheres é também, ou precisa ser, um estudo da situação social dos homens (SCOTT, 1995).

Para Vianna (2002, p. 89), estudos baseados em relações de gênero têm como intento a "busca (...) [de] superar o determinismo biológico, o qual, baseado apenas nas diferenças de sexo e reforçado por argumentações provenientes da medicina e das ciências biológicas, tenta justificar a caracterização de mulheres e homens como seres qualitativamente distintos".

Nesta mesma trilha, Lorber (1994, p. 35), afirma que o gênero não é “... the result of sex, procreation, physiology, anatomy, hormones, or genetic predispositions. It is produced and maintained by identifiable social processes and built into the general social structure and individual identities deliberately and purposefully ${ }^{2 \%}$.

Connel (1995, p. 189), argumenta que o "gênero é, nos mais amplos termos, a forma pela qual as capacidades reprodutivas e as diferenças sexuais dos corpos humanos são trazidas para a prática social e tornadas parte do processo histórico”. Assim, o uso do gênero como categoria de análise contribui, por exemplo, com o processo de desnaturalização das posições sociais ocupadas por homens e mulheres, o que, no concernente ao trabalho docente, demonstra estatuto de urgência.

\section{Trabalho docente e gênero}

\footnotetext{
2 “... o resultado do sexo, procriação, fisiologia, anatomia, hormônios ou predisposições genéticas. É produzido e mantido por processos sociais identificáveis e construídos na estrutura social geral e nas identidades individuais deliberada e propositadamente". (Tradução nossa).
} 
Dentro do processo de naturalização dos papéis sociais de mulheres e homens, argumentos de caráter biológico vieram, ao longo do tempo, sendo usados de forma constante, para a justificação das diferenças de ocupação no mercado de trabalho. O trabalho docente, juntamente com outras áreas como a enfermagem e trabalhos caracteristicamente assistenciais, vieram sendo, destarte, desde o final do século XIX, paulatinamente ocupados de forma majoritária por mulheres.

Mormente, o trabalho docente, foco do presente estudo, tem demonstrado ser um campo de importante reflexão na educação brasileira, haja vista esta ser atravessada por uma importante discrepância quando da distribuição de mulheres e homens em seus vários níveis. Tal discrepância remete a uma divisão interna aos níveis do sistema de ensino, sendo que há uma predominância de mulheres-professoras nas séries iniciais, havendo uma tendência a significativa diminuição dessa presença em níveis mais elevados do processo de escolarização (ALMEIDA, 1998; VIANNA, 2002 e DEMARTINI e ANTUNES, 1993). Tal discussão amplia, para além das questões de classe, embora estas não percam seu locus, a discussão acerca da educação escolar (VIANNA, 2002). Para Durães (2008), não se pode pensar nas relações de gênero, no tocante ao trabalho docente, sem falar de qualificação. Para a autora, são de três níveis as possibilidades do uso do termo: relacionando-o ao posto de trabalho, ao trabalhador(a) ou a uma construção social. Mais à frente esse aspecto será retomado mas, por hora, a autora esclarece:

A qualificação exigida para o trabalho docente na sociedade capitalista centraliza-se na base tecnológica, controle e racionalização das atividades. Cultural e socialmente, esses aspectos são reconhecidos como atributos masculinos e, por sua vez, são aqueles que dimensionam o trabalho qualificado na produção capitalista. Em direção contrária, as características de cuidado, carinho, zelo e exercício de atividades de coordenação motora fina são consideradas inerentes ou inatas à mulher, em vez de considerá-las como constitutivas em espaços anteriores e/ou externos ao local de trabalho (...) [grifos da autora] (DURÃES, 2008, s.p.).

Destarte, fica claro que o trabalho docente é prenhe de diferenças baseadas nas relações de gênero, ou melhor, a atividade docente encerra em si justificativas de ordem inatista, biologicista, naturalista, para as diferenças entre homens e mulheres que atuam como docentes. Retomando Vianna (2002), para quem o processo de socialização de mulheres e homens interfere, de forma ímpar, nas profissões que estes escolhem para si e na maneira como as exercem, seria simplista afirmar que a escolha pelo trabalho docente "foi sempre assim", ou que seja próprio da natureza de homens e mulheres, mas sim de "afirmar que as 
expressões da masculinidade e da feminilidade são historicamente construídas e referem-se aos símbolos culturalmente disponíveis em uma dada organização social, às normas expressas em suas doutrinas e instituições, à subjetividade e às relações de poder estabelecidas nesse contexto" (p. 90).

Desta forma, pareceu e parece haver uma distinção entre atributos femininos e masculinos baseados, respectivamente, no espaço privado e público. Nesta trilha, Bourdieu (1995?, s.p.), afirma com clareza:

Así, la división entre lo masculino y lo femenino continúa organizándose en torno a la oposición entre el interior y el exterior, entre la casa, con la educación de sus hijos, y el trabajo. Ha hallado su forma canónica en la burguesía, con la división entre el universo de la empresa, orientada hacia la producción y la utilidad, y el universo de la casa, orientado a la reproducción biológica, social y simbólica de la unidad doméstica, por ende a la gratuidad y a la futilidad aparentes de los gastos de dinero y tiempo, destinados a exhibir el capital simbólico y a redoblarlo mediante su manifestación ${ }^{3}$.

Assim, historicamente, a docência feminina nasce no final do século XIX, devido, principalmente, à expansão do ensino primário. No século XX, o processo de feminização do magistério se intensifica, sendo que nos anos de 20 e 30, as mulheres já eram maioria (VIANNA, 2002). Os motivos alegados e pensados sobre as razões disso perpassaram, no início, pela questão da progressiva desvalorização da profisssão docente, o que já começa a cair por terra devido a alguns indícios de que o trabalho docente já era desvalorizado quando ocupado pelos homens (DURÃES, 2002; ALMEIDA, 1998). Outra argumentação, deveras mais forte e ainda vigente de forma importante, foi a de que seriam próprios da mulher certos atributos interessantes à prática pedagógica.

No final do século passado, algumas correntes de pensamento que discutiam a existência de diferenças 'naturais' entre os sexos, tais como caráter, temperamento, tipo de raciocínio, acabaram influenciando todas as medidas adotadas na área educacional, acentuando ainda mais os preconceitos e a ordem estabelecida. Segundo essas correntes, a mulher, e apenas ela, era biologicamente dotada da capacidade de socializar crianças, como parte de suas funções maternas (DEMARTINI e ANTUNES, 1993, p. 7).

Assim, afirmar a existência de uma natureza feminina e masculina facilita o processo de justificação das diferenças notadas na sociedade, diferenças essas que ainda hoje se

\footnotetext{
3 “Assim, a divisão entre homens e mulheres continua a ser organizada em torno da oposição entre o interior e o exterior, entre a casa, com a educação dos filhos, e o trabalho. Tendo encontrado sua forma canônica na burguesia, com a divisão entre o universo da empresa, orientados para produção e a utilidade, e o universo da casa, orientado para a reprodução biológica, social e simbólica da unidade doméstica, por isso a aparente gratuidade e futilidade dos gastos com dinheiro e tempo, destinados a exibir o capital simbólico e de redobrá-lo mediante sua demonstração". (tradução nossa).
} 
mostram importantes, tanto no tocante à remuneração quanto à possibilidade de ocupar cargos mais altos, estes últimos invariavelmente ocupados por homens (DEMARTINI e ANTUNES, 1993).

A título de reflexão, pensa-se ser possível pensar que o predomínio feminino no magistério, principalmente primário, também guarda estreita relação com a proposta de educação de uma dada sociedade. Por que as características pretensamente femininas são interessantes para a docência? Articula-se aqui uma determinada visão de infância, que é também construída socialmente (ARIÈS, 1981).

Retomando a questão da qualificação do trabalho docente na estrutura capitalista de produção, retorna-se a Durães (2008), para quem a definição de qualificação do trabalhador refere-se "às características das atividades executadas ou pertencentes ao universo masculino" (s.p.). A questão que se coloca é que a qualificação, no trabalho docente, parece basear-se na dicotomia entre as características inatas das mulheres $\mathrm{e}$ as características obtidas e conquistadas pelos homens, principalmente em termos de formação.

\begin{abstract}
Em síntese, os critérios que estão postos para a identificação do trabalho docente qualificado são determinados a partir do universo masculino. A sociedade tende a reconhecer o trabalho feminino, em especial, aquele realizado na esfera doméstica, como decorrente do âmbito da natureza, das condições inatas e do talento. Em outras palavras, a mulher-professora é portadora de talentos e o homem-professor, de qualificação. (DURÃES, 2008, s.p.).
\end{abstract}

Outro aspecto, que deste decorre, e que em muito esclarece uma constatação que será melhor discutida à frente, no concernente aos dados empíricos levantados para a presente pesquisa, é a de que há, ainda, uma desigual distribuição de mulheres e homens nos diferentes níveis de escolarização, ou melhor, há mais mulheres nas séries iniciais e mais homens nas séries mais avançadas.

\title{
A implantação do ensino superior no norte de Minas Gerais: a FAFIL/FUNM
}

O ensino superior brasileiro desenvolveu-se de forma peculiar e recorrente, em várias regiões do país, mas caracteristicamente em regiões tidas como mais desenvolvidas, em grandes centros urbanos ou em locais que se pretendia viessem a ser grandes centros urbanos (CUNHA, 2003). As universidades brasileiras foram formadas, no mais das vezes, a partir da aglomeração de faculdades isoladas já em funcionamento, e o processo de interiorização do ensino superior deu-se por volta de meados do século XX, parte este de ideais de modernização e expansão do capital em direção ao interior do país, até então visto como local 
de atraso. O olhar dirige-se, aqui, para a região norte do estado de Minas Gerais, região esta que era, até a década de 1960, nos dizeres de Jardim et al (2002, p. 18-19):

... carente de infraestrutura, baixo índice de industrialização, renda per capita e urbanização. Os problemas sociais decorrentes das grandes diferenças socioeconômicas indicavam a necessidade da formação de pessoal qualificado. Uma região com ensino precário apresentando altos índices de analfabetismo, carente de professores habilitados e que presenciava todos os anos seus jovens interromperem seus estudos por falta de opção, ou aqueles mais afortunados migrarem para outras regiões a fim de continuarem sua formação e, na sua maioria, não mais retornando ${ }^{4}$.

Com este panorama histórico, um grupo de mulheres, ainda no final da década de 1950, iniciou um movimento para a implantação de uma unidade de ensino superior na região. Segundo Maia e Cordeiro (2002), o grupo era formado por Isabel Rebello de Paula, Maria Isabel Figueiredo Sobreira, Maria da Consolação de Magalhães Figueiredo, Maria Florinda Pires Ramos e Maria Dalva Dias de Paulo. Estas, ainda segundo as autoras, buscaram apoio em autoridades regionais e na comunidade local, chegando a proferir palestras sobre a situação do ensino na região, ancorando nesta, no mais das vezes, a necessidade da implantação do ensino superior, ou seja, formar professores e professoras para a expansão do ensino secundário. O nome "A escola das meninas", a que se fez menção no título do presente artigo é referência a uma fala de Isabel Rebello de Paula, em entrevista concedida a Maia e Cordeiro (2002), afirmando que assim 'foi conhecida a FAFIL nos seus primeiros tempos por seus alunos, em sua maioria, mais idosos que as fundadoras e primeiras mestras” (p. 55).

A FAFIL data, então, de dois de agosto de 1963, tendo sido mantida pela Fundação Educacional Luiz de Paula - FELP, entidade sem fins lucrativos que havia sido instituída em 1961 com o intuito de criar, instalar e manter estabelecimentos de ensino secundário no norte de Minas, até 1965, quando foi incorporada à FUNM. Esta última, tendo sido criada oficialmente em vinte e quatro de maio de 1962, somente iniciou suas atividades em 1964 (MAIA e CORDEIRO, 2002).

Cabe acrescer que a década de 1960 foi um momento histórico de importante reformulação pedagógica. Segundo Souza (2008), as maiores transformações deram-se no tocante ao ensino secundário, quando o "conteúdo marcadamente humanista até então predominante, gozando de enorme legitimidade social, foi substituído pela cultura científica e

\footnotetext{
${ }^{4} \mathrm{O}$ texto citado é parte integrante de um livro editado em comemoração aos quarenta anos da Universidade Estadual de Montes Claros - UNIMONTES, nome que recebeu a Fundação Universidade Norte-Mineira FUNM quando da sua estadualização, em 1989, cujo reconhecimento oficial só viria ocorrer em 1994.
} 
técnica orientada para o trabalho" (p. 228). Vianna (2002) parece ter uma visão próxima quando afirma que essa década foi marcada por uma expansão desenfreada dos ginásios.

Tais transformações, não inadvertidamente, iam ao encontro aos ideais da política desenvolvimentista ${ }^{5}$, cujo auge ocorreu na mesma década. Para Fonseca (2005) um jogo de forças de quatro grupos, que defendiam cada qual com os discursos que lhes cabiam, o ideário do movimento que ficou conhecido como "desenvolvimentismo". Seriam eles: a) a defesa da industrialização; b) a defesa do intervencionismo pró-crescimento; c) o nacionalismo e d) o positivismo. Assim, para Mendonça et al (2006, p. 98):

... a superação da situação de dependência econômica e a busca de emancipação social orientaram um conjunto de ações no âmbito do debate intelectual e da formulação de projetos de reorientação das políticas de Estado, que visavam a articulação entre industrialização, desenvolvimento científico e renovação educacional.

Destarte, parece haver muito desse movimento no processo de implantação do ensino superior no norte de Minas, principalmente nas alegações ${ }^{6}$ das mulheres que estiveram envolvidas nesse processo que, como visto, perpassava muito pela defesa da ampliação da rede de ensino, principalmente secundário.

Segundo Maia e Cordeiro (2002), as mulheres citadas eram recém formadas ${ }^{7}$, fato que pode ter feito com que as mesmas tivessem se formado sob forte influência do reformismo pedagógico do período, tal como dito, quando a formação humanista, generalista, passa, mais do que nunca, a ser substituída pela formação técnico-científica, em virtude das necessidades impostas pelo capital no ininterrupto processo de progresso técnico e tecnológico próprio do sistema capitalista.

Nessa trilha, a expansão da rede de ensino secundário no norte de Minas ter-se-ia dado em virtude da necessidade do desenvolvimento econômico ${ }^{8}$ da região, da formação de mão-

\footnotetext{
${ }^{5}$ Compartilha-se aqui com a definição de desenvolvimentismo de Chaves (2006, p. 709), quando a mesma afirma que o "... pensamento desenvolvimentista situa-se no âmbito da economia política, e ancora-se nas ideias de Keynes. Em oposição ao liberalismo neoclássico, que acredita na regulação automática do mercado, defende que o Estado deve ser o principal condutor do desenvolvimento econômico, e não simplesmente gerir a coisa pública ou regular as atividades privadas".

${ }^{6}$ Cabe apenas ressaltar que a alegação de que o norte de Minas dispunha de uma rede de ensino precária não é irreal, mas ao contrário. Os números falam por si quando são relatados, como por exemplo: nos $121.000 \mathrm{~km}^{2} \mathrm{da}$ região, com uma população de cerca de um milhão de habitantes, havia apenas 57 estabelecimentos de ensino secundário, sendo que $91,24 \%$ deles eram de iniciativa privada e somente $8,76 \%$ eram públicos.

${ }^{7}$ Embora não tenha sido possível verificar com exatidão em que cursos as mesmas graduaram-se, pode-se afirmar que tratavam-se de cursos ligados à Licenciatura, como Pedagogia e Letras.

${ }^{8}$ Faz-se necessário esclarecer que se utiliza aqui a ideia de desenvolvimento econômico em um momento histórico em que este ainda tinha uma imagem de suficiente à superação das precárias condições de vida da população, algo que só começa a ser desconstruído em meados da década de 1970, com o texto de Celso Furtado (1981).
} 
de-obra qualificada essencial para tanto, ou seja, da expansão do capital a regiões ainda não integradas ao sistema.

\section{Homens e mulheres na FAFIL/FUNM}

Buscou-se levantar, por meio de pesquisa documental, a relação de mulheres e homens entre os candidatos ingressantes dos cinco primeiros anos de funcionamento da FAFIL/FUNM ${ }^{9}$, crendo que tal discrepância, como ver-se-á, possibilita um maior espectro de compreensão da realidade educacional da região no referido período. Foram levantados, então, dados referentes dos anos de 1964, entrada das primeiras turmas, até 1968, quando da abertura de três novos cursos, como pode ser visto na tabela 1.

\begin{tabular}{|c|c|c|c|c|c|c|c|c|c|c|}
\hline ANO & \multicolumn{2}{|c|}{1964} & \multicolumn{2}{c|}{1965} & \multicolumn{2}{c|}{1966} & \multicolumn{2}{c|}{1967} & \multicolumn{2}{c|}{1968} \\
\hline CURSO / SEXO & M & H & M & H & M & H & M & H & M & H \\
\hline HISTÓRIA & 15 & 11 & 2 & 8 & 7 & 5 & 11 & 1 & 23 & 4 \\
\hline PEDAGOGIA & 37 & 8 & 10 & 2 & 27 & 1 & 26 & 0 & 49 & 1 \\
\hline LETRAS & 16 & 22 & 4 & 3 & 6 & 0 & 5 & 4 & 22 & 8 \\
\hline GEOGRAFIA & 8 & 12 & 7 & 4 & 8 & 4 & 5 & 5 & 12 & 1 \\
\hline CIÊNCIAS SOCIAIS & - & - & - & - & - & - & - & - & 24 & 7 \\
\hline MATEMÁTICA & - & - & - & - & - & - & - & - & 15 & 46 \\
\hline FILOSOFIA & - & - & - & - & - & - & - & - & 0 & 10 \\
\hline TOTAL & $\mathbf{7 6}$ & $\mathbf{5 3}$ & $\mathbf{2 3}$ & $\mathbf{1 7}$ & $\mathbf{4 8}$ & $\mathbf{1 0}$ & $\mathbf{4 7}$ & $\mathbf{1 0}$ & $\mathbf{1 4 5}$ & $\mathbf{7 7}$ \\
\hline
\end{tabular}

Tabela 1: Distribuição dos candidatos, mulheres e homens, ingressantes na FAFIL/FUNM, entre 1964 e 1968. Fonte: Secretaria geral - UNIMONTES.

Como se pode notar, até 1967 somente havia os cursos de História, Pedagogia, Letras e Geografia, e que a partir de 1968, iniciam-se os cursos de Ciências Sociais, Matemática e Filosofia. Assim, de um total de 506 ingressantes nestes cinco anos, em todos os cursos, 339 (67\%) eram mulheres e 167 (33\%), homens. Mais interessante, porém, são as discrepâncias percebidas na desigual distribuição de homens e mulheres nos cursos oferecidos. As tabelas 2, 3 e 4 demonstram as taxas percentuais dessa distribuição por ano.

\footnotetext{
${ }^{9}$ Cabe aqui acrescer que, embora os dados empíricos explanados e discutidos remetam-se ao corpo discente, por se tratarem todos de cursos de licenciatura, de formação docente, pensa-se que estabelece-se um ciclo de reprodução das relações de gênero, já que os primeiros alunos vieram a tornarem-se, quando formados, professoras e professores.
} 


\begin{tabular}{|l|c|c|c|c|c|c|c|c|c|c|}
\hline \multicolumn{1}{|c|}{ ANO } & \multicolumn{5}{c|}{1964} & \multicolumn{5}{c|}{1965} \\
\hline \multicolumn{1}{|c|}{ SEXO } & $\mathbf{M}$ & $\%$ & $\mathbf{H}$ & $\mathbf{\%}$ & TOTAL & $\mathbf{M}$ & $\mathbf{\%}$ & $\mathbf{H}$ & $\%$ & TOTAL \\
\hline HISTÓRIA & 15 & 57,69 & 11 & 42,31 & 26 & 2 & 20,00 & 8 & 80,00 & 10 \\
\hline PEDAGOGIA & 37 & 82,22 & 8 & 17,78 & 45 & 10 & 83,33 & 2 & 16,67 & 12 \\
\hline LETRAS & 16 & 42,11 & 22 & 57,89 & 38 & 4 & 57,14 & 3 & 42,86 & 7 \\
\hline GEOGRAFIA & 8 & 40,00 & 12 & 60,00 & 20 & 7 & 63,64 & 4 & 36,36 & 11 \\
\hline CIÊNCIAS SOCIAIS & - & - & - & - & - & - & - & - & - & - \\
\hline MATEMÁTICA & - & - & - & - & - & - & - & - & - & - \\
\hline FILOSOFIA & - & - & - & - & - & - & - & - & - & - \\
\hline TOTAL & $\mathbf{7 6}$ & $\mathbf{5 8 , 9 1}$ & $\mathbf{5 3}$ & $\mathbf{4 1 , 0 9}$ & $\mathbf{1 2 9}$ & $\mathbf{2 3}$ & $\mathbf{5 7 , 5 0}$ & $\mathbf{1 7}$ & $\mathbf{4 2 , 5 0}$ & $\mathbf{4 0}$ \\
\hline
\end{tabular}

Tabela 2: Distribuição dos candidatos, mulheres e homens, ingressantes na FAFIL/FUNM, em números absolutos e percentuais, em 1964 e 1965. Fonte: Secretaria geral - UNIMONTES.

\begin{tabular}{|l|c|c|c|c|c|c|c|c|c|c|}
\hline \multicolumn{1}{|c|}{ ANO } & \multicolumn{5}{c|}{1966} & \multicolumn{5}{c|}{1967} \\
\hline \multicolumn{1}{|c|}{ SEXO } & $\mathbf{M}$ & $\%$ & $\mathbf{H}$ & $\mathbf{\%}$ & TOTAL & $\mathbf{M}$ & $\%$ & $\mathbf{H}$ & $\mathbf{\%}$ & TOTAL \\
\hline HISTÓRIA & 7 & 58,33 & 5 & 41,67 & 12 & 11 & 91,67 & 1 & 8,33 & 12 \\
\hline PEDAGOGIA & 27 & 96,43 & 1 & 3,57 & 28 & 26 & 100,00 & 0 & 0,00 & 26 \\
\hline LETRAS & 6 & 100,00 & 0 & 0,00 & 6 & 5 & 55,56 & 4 & 44,44 & 9 \\
\hline GEOGRAFIA & 8 & 66,67 & 4 & 33,33 & 12 & 5 & 50,00 & 5 & 50,00 & 10 \\
\hline CIÊNCIAS SOCIAIS & - & - & - & - & - & - & - & - & - & - \\
\hline MATEMÁTICA & - & - & - & - & - & - & - & - & - & - \\
\hline FILOSOFIA & - & - & - & - & - & - & - & - & - & - \\
\hline TOTAL & $\mathbf{4 8}$ & $\mathbf{8 2 , 7 6}$ & $\mathbf{1 0}$ & $\mathbf{1 7 , 2 4}$ & $\mathbf{5 8}$ & $\mathbf{4 7}$ & $\mathbf{8 2 , 4 6}$ & $\mathbf{1 0}$ & $\mathbf{1 7 , 5 4}$ & $\mathbf{5 7}$ \\
\hline
\end{tabular}

Tabela 3: Distribuição dos candidatos, mulheres e homens, ingressantes na FAFIL/FUNM, em números absolutos e percentuais, em 1966 e 1967. Fonte: Secretaria geral - UNIMONTES.

\begin{tabular}{|l|c|c|c|c|c|}
\hline \multicolumn{1}{|c|}{ ANO } & \multicolumn{5}{c|}{1968} \\
\hline \multicolumn{1}{|c|}{ SEXO } & M & $\mathbf{\%}$ & $\mathbf{H}$ & $\mathbf{\%}$ & TOTAL \\
\hline HISTÓRIA & 23 & 85,19 & 4 & 14,81 & 27 \\
\hline PEDAGOGIA & 49 & 98,00 & 1 & 2,00 & 50 \\
\hline LETRAS & 22 & 73,33 & 8 & 26,67 & 30 \\
\hline GEOGRAFIA & 12 & 92,31 & 1 & 7,69 & 13 \\
\hline CIÊNCIAS SOCIAIS & 24 & 77,42 & 7 & 22,58 & 31 \\
\hline MATEMÁTICA & 15 & 24,59 & 46 & 75,41 & 61 \\
\hline FILOSOFIA & 0 & 0,00 & 10 & 100,00 & 10 \\
\hline TOTAL & $\mathbf{1 4 5}$ & $\mathbf{6 5 , 3 2}$ & $\mathbf{7 7}$ & $\mathbf{3 4 , 6 8}$ & $\mathbf{2 2 2}$ \\
\hline
\end{tabular}

Tabela 4: Distribuição dos candidatos, mulheres e homens, ingressantes na FAFIL/FUNM, em números absolutos e percentuais, em 1968. Fonte: Secretaria geral - UNIMONTES 
Pode-se notar, de forma clara, que ao longo desses cinco primeiros anos de funcionamento da FAFIL, o número de mulheres ingressantes sempre foi superior ao de homens ingressantes. Além disso, nos quatro primeiros anos, tal diferença aumentou, progressivamente, principalmente devido à elevada procura das mulheres pelo curso de pedagogia. O decréscimo ocorrido em 1968 pode ser explicado pelo início dos cursos de Ciências Sociais, Matemática e Filosofia, sendo que apenas o primeiro obteve maioria de mulheres, e aventa-se a possibilidade de que os dois últimos tenham se dado devido à área da matemática ser socialmente tida como própria do homem, pois exige algo que dele é próprio, o raciocínio lógico, e a procura dos seminaristas pelo curso de filosofia. No entanto, a busca das mulheres pelo curso de pedagogia merece uma reflexão mais detida. O gráfico 1 é transparente quanto a essa constatação.

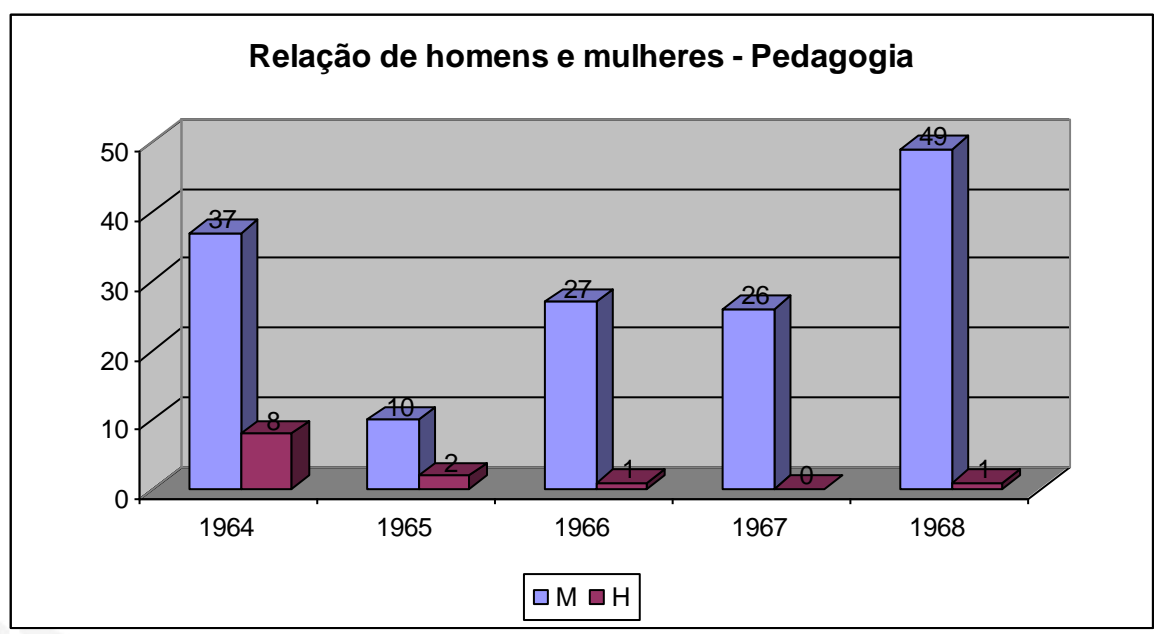

Gráfico 1: Relação de homens e mulheres no curso de pedagogia da FAFIL, entre 1964 e 1968. Fonte: Secretaria geral - UNIMONTES

Tal fato parece corroborar com a noção que Bourdieu (1995) possui do sexismo que impregna as divisões no trabalho, atravessadas pela questão de gênero. O faz quando afirma que o "sexismo es un esencialismo: al igual que el racismo, étnico o clasista, busca atribuir diferencias sociales históricamente construidas a una naturaleza biológica que funciona como una esencia de donde se deducen de modo implacable todos los actos de la existência ${ }^{10}$ (p. 1112).

\footnotetext{
10 "sexismo é um aspecto essencial: assim como o racismo, étnico ou de classe, busca atribuir diferenças sociais construídas historicamente a uma natureza biológica que funciona como uma essência de onde são deduzidos de forma implacável todos os atos de existência". (tradução nossa).
} 
Assim, a procura das mulheres pelo curso de pedagogia acaba por ser explicada por um intrincado processo que culmina por reificar a naturalização das diferenças entre mulheres e homens ou, nos dizeres de Bourdieu (1995?, s.p.):

El trabajo milenario de socialización de lo biológico y de biologización de lo social, al revertir la relación entre causa y efecto hace aparecer una construcción social naturalizada (los habitus diferentes, fruto de las diversas condiciones producidas socialmente) como la justificación natural de la representación arbitraria de la naturaleza que le dio origen y de la realidad y la representación de ésta ${ }^{11}$ [grifo nosso].

De maneira mais minuciosa, os espaços de trabalho ocupados por mulheres aproveitam de suas habilidades e inclinações "naturais", tanto no espaço público como no privado, como bem colocado por Vianna (2002, p. 93):

Criam-se, assim, vários estereótipos sobre homens e mulheres: agressivos, militaristas, racionais, pra eles; dóceis, relacionais, afetivas, para elas. Em decorrência, funções como alimentação, maternidade, preservação, educação e cuidado com os outros ficam mais identificadas com os corpos e as mentes femininas, ganhando, assim, um lugar inferior na sociedade, quando comparadas às funções tidas como masculinas.

O curso de pedagogia buscava formar professoras e professores para atuar nas séries iniciais do processo de escolarização, fato que pode explicar a imensa maioria de mulheres nesse curso. Já que o "exercício do magistério representava um prolongamento das funções maternas e instruir e educar crianças era considerado aceitável para as mulheres" (ALMEIDA, 1998, p. 62).

É preciso reconhecer, sem dúvida, que a implantação do ensino superior na região configurou-se enquanto significativa alternativa de vida às mulheres da região, haja vista as imensas dificuldades para prosseguir os estudos em outros locais do país. Para Almeida (1998) houve, nesse período, uma grande movimento de resistência das mulheres quanto à saída do espaço privado e à conquista do espaço público. No presente caso, sem dúvida ocorreu, nesses cinco primeiros anos de funcionamento da FAFIL, uma busca maior das mulheres pela formação superior, como pode ser notado no gráfico 2, abaixo.

\footnotetext{
11 "O trabalho milenar de socialização do biológico e biologização do social, ao inverter a relação entre causa e efeito faz aparecer uma construção social naturalizada (o hábitos diferentes, fruto das diversas condições socialmente produzidas), como a justificação natural da representação arbitrária da natureza que lhe deu origem e da realidade e da representação desta". (tradução nossa).
} 


\section{Proporção de homens e mulheres na FAFIL}

$(1964 / 68)$

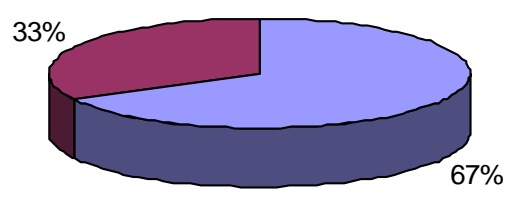

$\square$ Mulheres $\square$ Homens

Gráfico 2: Proporção de homens e mulheres nos cursos da FAFIL, entre 1964 e 1968. Fonte: Secretaria geral - UNIMONTES

Abrindo um parêntese, cabe acrescer que existiam, além da FAFIL, outras quatro faculdades ligadas à FUNM, seriam elas: a Faculdade de Direito (FADIR), a Faculdade de Medicina (FAMED), a Faculdade de Administração e Finanças (FADEC) e a Faculdade de Educação Artística (FACEART). Mesmo estas não sendo objeto de análise do presente estudo, remete-se a elas em virtude de alguns dados levantados por Maia e Cordeiro (2002), referentes aos professores e professoras de cada uma delas em seus primeiros anos.

Os dados, que podem ser vistos no gráfico 3, demonstram que, mesmo entre os docentes, que obviamente tiveram suas formações em cursos correlatos aos que vieram depois lecionar, há uma distribuição deveras desigual de mulheres e homens.

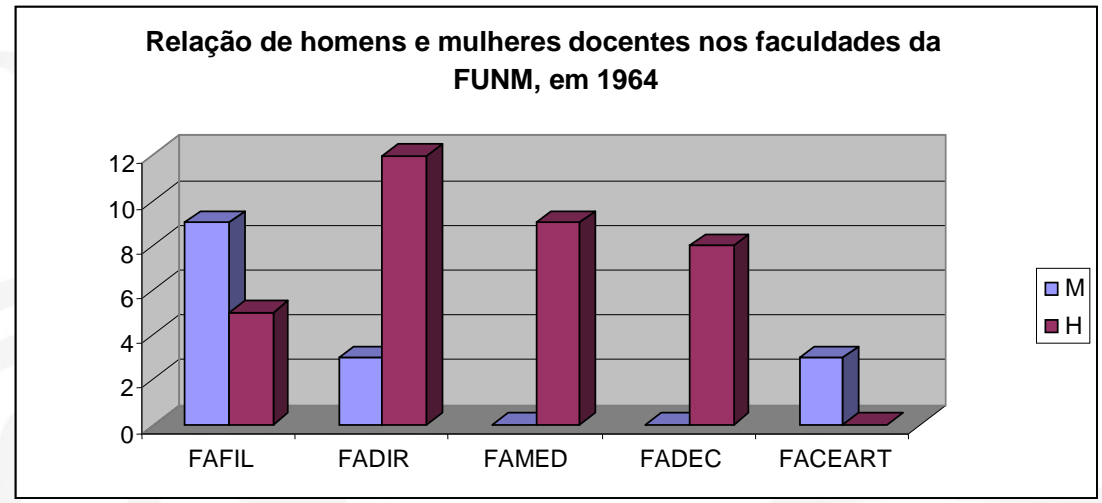

Gráfico 3: Relação de homens e mulheres docentes nas faculdades da FUNM, em 1964. Fonte: MAIA e CORDEIRO (2002)

Como se pode notar há forte predomínio de mulheres na FAFIL e FACEART, onde argumenta-se que são necessárias aquelas características tidas como femininas, como sensibilidade, carinho, zelo, algo de cunho essencialmente emocional, em detrimento de um predomínio masculino nas demais faculdades, áreas em que seriam, então, exigidas características essencialmente racionais e analíticas, tidas como próprias do homem. Assim, o 
predomínio de mulheres na FAFIL parece também sofrer influência das outras faculdades da FUNM.

\section{À guisa de conclusão}

Desta forma, a denominação "A escola das meninas" parece ser extensiva ao corpo discente da FAFIL/FUNM, e não apenas restringir-se ao corpo docente. A representatividade feminina, principalmente no curso de pedagogia, denota que o processo de implantação do ensino superior no norte de Minas é atravessado por questões da ordem do gênero, e que este, enquanto categoria analítica, em muito elucida a concretude das relações sociais no período. A procura majoritariamente feminina pela pedagogia implica que só as mulheres possuiriam aquelas características necessárias no trato com a docência de nível primário.

A implantação do ensino superior no norte de Minas se mostra, por isso, mais um exemplo de que as relações de gênero influenciam de forma importante a busca de mulheres e homens por um curso de ensino superior, dadas as justificativas socialmente construídas de que estes possuem características que lhes são próprias, naturais, inatas.

O processo, portanto, que leva a uma desigual distribuição de homens e mulheres no trabalho docente, parecendo este estar relacionado às características do posto de trabalho. Em outras palavras, o curso de pedagogia da FAFIL, como visto, objetivava formar docentes para níveis de educação infantil ou primária, e há neste um predomínio absoluto de mulheres. A profissão docente, para Almeida (1998), foi historicamente constituída enquanto alternativa ao casamento, para as mulheres, dentro do seu processo de emancipação.

Trazendo para o contexto norte-mineiro do período tratado, pensa-se que a implantação do ensino superior tornou-se uma alternativa, do caráter acima exposto, para as mulheres da cidade e região. Seriam necessários outros estudos para confirmar de forma sólida tal hipótese, haja vista as informações levantadas para esta pesquisa não privilegiarem informações que possibilitassem tal confirmação.

A manutenção das mulheres no âmbito exclusivamente doméstico, que é entendido por Oliveira e Ariza (1997) como uma forma de exclusão social, teria sido superado, neste momento histórico, em parte. Isso porque a permanência delas no magistério primário poderia, da mesma forma, ser vista como um processo de exclusão, deveras mais sutil do ponto de vista ideológico, mas exclusão.

Surgem, então, perguntas que podem servir de estopim a novas pesquisas sobre "A escola das meninas": quais eram os objetivos das alunas ao candidatarem-se a um curso 
superior? Por que escolhiam, em sua maioria, o curso de pedagogia? Que aspectos, em nível macro e microssociológico, influenciaram tais escolhas? O que representou para essas mulheres adentrar em um curso superior? Ficam, tais questionamentos, em aberto e direcionando novas possíveis pesquisas que possam esclarecer essa dimensão da história local, em mesmo tempo em que lançarão luz à naturalização dos papéis sociais de mulheres e homens no campo educacional.

\section{Referências bibliográficas}

ALMEIDA, J. S. Mulher e educação: a paixão pelo possível. São Paulo: Ed. Unesp, 1998. ARIÉS, P. História social da criança e da família. $2^{\mathrm{a}}$ edição. Rio de Janeiro: LTC Editora, 1981.

BOURDIEU, P. (1995). La dominación masculina. Disponível em: http://www.udg.mx/laventana/libr3/bordieu.html\#cola. Acessado em: 18/12/2008.

CHAVES, Miriam Waidenfeld. Desenvolvimentismo e pragmatismo: o ideário do Mec nos anos 1950. Cadernos de Pesquisa. v. 36, n. 129, p. 705-725, set./dez, 2006.

CONNEL, R. Políticas de masculinidade. Educação e Sociedade. v. 20, n², julho-dezembro. p. 185-206, 1995.

CUNHA, Luiz Antonio. Ensino superior e universidade no Brasil. In: LOPES, Eliane Marta Teixeira; FILHO, Luciano Mendes Faria e VEIGA, Cynthia Greive. 500 anos da educação no Brasil. $3^{\text {a }}$ edição. Belo Horizonte: Autêntica, 2003.

DEMARTINI, Z. B. F. e ANTUNES, F. F. (1993). Magistério primário: profissão feminina, carreira masculina. Cad. Pesq. São Paulo, n. 86, p. 5-14, ago. Disponível em: http://www.fcc.org.br/pesquisa/publicacoes/cp/arquivos/892.pdf. Acessado em: 12/12/2008.

DURÃES, S. J. A. Sobre algumas relações entre qualificação, gênero e trabalho docente. 2008. (Mimeo).

DURÃES, S. J. A. (2002). Escolarização das diferenças: qualificação do trabalho docente e gênero em Minas Gerais (1860-1906). 285p. Tese (Doutorado). Pontifícia Universidade Católica de São Paulo, Departamento de Educação: História, Política e Sociedade. Disponível em:http://www.fae.ufmg.br/portalmineiro/portal/conteudo/hiseduminas/teses/tese_sarahjane.p df. Acessado em: 22/10/2008.

FONSECA, Paulo Cezar Dutra. Gênese e Precursores do Desenvolvimentismo no Brasil. PPGE/UFRGS, Textos para Discussão, 2005.

JARDIM, A. F. C. et al. A genealogia de uma universidade: de 1962 a 1989. In: CALEIRO, R. C. L. e PEREIRA, L. M. (org.). UNIMONTES: 40 anos de história. Montes Claros, MG: Ed. UNIMONTES, 2002.

LORBER, J. "Night to his day": the social construction of gender. In: Paradoxes of gender. New York: Yale University. p. 13-36, 1994.

MAIA, C. de J. e CORDEIRO, F. L. As faculdades da FUNM. In: CALEIRO, R. C. L. e PEREIRA, L. M. (org.). UNIMONTES: 40 anos de história. Montes Claros, MG: Ed. UNIMONTES, 2002.

MENDONÇA, Ana Waleska P. C. et al. Pragmatismo e desenvolvimentismo no pensamento educacional brasileiro dos anos de 1950/1960. Revista Brasileira de Educação. v. 11, n. 31, jan./abr, 2006. 
OLIVEIRA, O. e ARIZA, M. División sexual del trabajo y exclusión social. Revista Latinoamericana de Estudios del trabajo. Ano 3, no 5. p. 183-202, 1997.

SCOTT, J. Gênero: uma categoria útil de análise histórica. Educação e Realidade. v. 20, n², julho-dezembro. p. 71-100, 1995.

SOUZA, R. F. de. História da organização do trabalho escolar e do currículo no século XX: ensino primário e secundário no Brasil. São Paulo: Cortez, 2008.

VIANNA, C. P. O sexo e o gênero na docência. Cadernos Pagu. n ${ }^{\circ}$ 17-18, São Paulo, Unicamp, p. 81-104, 2002. 